\title{
Pemerolehan Bahasa pada Anak Usia Dini di Desa Hadiwarno Kecamatan Mejobo Kabupaten Kudus
}

\author{
Luthfa Nugraheni*, Mohammad Noor Ahsin \\ Universitas Muria Kudus \\ *email: luthfanugraheni@umk.ac.id
}

\begin{abstract}
Language is a means used to communicate in everyday life. Through good and effective language, every buman being can understand what the utterances mean. Language acquisition will be seen in early childhood. At that age children go through the learning process in obtaining language both from what is seen and taught. The purpose of this study was to look at language acquisition in early childhood in Hadiwarno Village, Mejobo District, Kudus Regency. This research method is descriptive qualitative by describing the data that has been obtained. The data technique in this article is to use observation, interview and documentation techniques. This teori in paper is psicolinguistic. The results of this study are the words of family members, objects in the bouse, objects outside the house, means of transportation, animals, colors, names of fruits and natural phenomena that get the highest data acquisition is mentioning the names of family members. This is because, in the process of acquiring language that occurs in early childhood, more words will be formed from the family.

Keywords: psikolinguistic; process of language acquisition; early childhood
\end{abstract}

\section{ABSTRAK}

Bahasa merupakan sarana yang digunakan untuk berkomunikasi di dalam kehidupan sehari-hari. Melalui bahasa yang baik dan efektif setiap manusia dapat memahami maksud ujaran yang dituturkan. Pemerolehan bahasa akan terlihat pada anak usia dini. Di usia tersebut anak melalui proses belajar dalam memperoleh bahasa baik dari yang dilihat dan diajarkan. Tujuan dari penelitian ini adalah mengetahui pemerolehan bahasa pada anak usia dini di Desa Hadiwarno Kecamatan Mejobo Kabupaten Kudus. Metode penelitian ini adalah deskriptif kualitatif dengan menggambarkan data-data yang telah diperoleh. Kajian yang digunakan dalam penelitian ini adalah psikolinguistik. Teknik pengumpulan data dalam artikel ini adalah menggunakan teknik observasi, wawancara dan dokumentasi. Hasil dari penelitian ini adalah dari kata anggota keluarga, benda dalam rumah, benda di luar rumah, alat transportasi, hewan, warna, nama buah-buahan dan fenomena alam. Pemerolehan data tertinggi adalah menyebutkan nama anggota keluarga. Hal ini dikarenakan, dalam proses pemerolehan bahasa yang terjadi pada anak usia dini, kosa kata akan lebih banyak terbentuk dari keluarga

Kata Kunci: psikolinguistik; proses pemerolehan bahasa; anak usia dini

$$
\text { Submitted Apr 20, } 2021 \text { | Revised May 03, } 2021 \text { | Accepted May 05, } 2021
$$

\section{Pendahuluan}

Pemerolehan bahasa (native language) dapat diartikan sebagai proses penguasaan bahasa pada diri anak sejak usia dini. Pemerolehan bahasa berkaitan dengan penguasaan bahasa yang dilakukan anak secara natural pada waktu belajar bahasa ibu (Nurjamiaty, 2015; Fatmawati, 2015; Syaprizal, 2019; Suardi, et al., 2019). Pemerolehan bahasa akan terus berkembang seiring dengan bertambahnya usia anak. Pemerolehan bahasa pertama sangat berkaitan dengan perkembangan sosial anak dan pembentukan identitas social. Mempelajari bahasa pertama merupakan salah satu perkembangan menyeluruh anak menjadi anggota suatu masyarakat.

Pemerolehan bahasa yang pertama pada anak ketika mereka belajar dari bahasa ibu (Puspitasari \& Safitri, 2016; Hastuti, 2018). Dengan demikian, dalam proses anak menguasai bahasa ibu dapat disebut dengan pemerolehan. Pada saat anak belajar memeroleh suatu bahasa, maka dalam hal ini anak mendapatkan kemampuan untuk menangkap, menghasilkan, dan menggunakan kata dipahami dan berkomunikasi. Perkembangan bahasa anak merupakan kemampuan anak untuk memberikan respon terhadap suara, mengikuti perintah, dan berbicara sopan. Perkembangan bahasa berlangsung sangat cepat dan menjadi landasan dalam perkembangan selajutnya pada masa balita (Safitri, 2017). 
Perkembangan bahasa pada anak usia dini melalui pemerolehan bahasa merupakan salah satu tahap penting dalam rangka transmisi bahasa agar terhindar dari kepunahan (Mayasari, 2018).

Kedudukan bahasa dalam kehidupan sehari-hari ialah sebagai sarana untuk berkomunikasi (Tarigan, 2008). Oleh sebabnya kapasitas proses pemerolehan bahasa meliputi aspek sintaksis, fonetik, dan kosa kata. Teori yang digunakan dalam kajian ini adalah psikolinguistik. Psikolinguistik merupakan sebuah ilmu yang terdiri dari psikologi dan linguistik (Hakim, 2012). Psikologi merupakan ilmu yang mempelajari mental anak dalam memproduksi bahasa sedangkan linguistik adalah sebuah cabang ilmu yang mempelajari tentang bahasa, tambah (Handke, 2012).

Pramita (2019) menyampaikan dalam pemerolehan bahasa anak usia dini menyangkut aspek fonologi, sintaksis dan semantik. Akan tetapi aspek fonologi yang perlu dikuasai anak terlebih dahulu. hal ini dikarenakan bahwa dari anak melafalkan dalam mengucapkan sesuatu perlu melewati tahapan fonologis. Sementara Sasangka (2000) dalam umur 2 dan 3 tahun anak sudah mampu mengungkapkan kata-kata mudah dan sulit. Akan tetapi ketika anak telah mampu mengungkapkan kata-kata dan menirukan lirik lagu anak belum mengetahui isi dan makna dari sebuah ujaran yang ditirukan anak. Oleh sebabnya aspek fonologislah yang pertama didapatkan oleh sang anak.

Viandari (2019) menambahkan bahwa anak pra sekolah kerap menemui kesulitan untuk melafalkan huruf konsonan, misalkan pada huruf "R" motor, trotoar dan lain sebagainya. Pada umur dua tahun anak sudah dapat melafalkan dua kata meskipun agak pelo atau kurang jelas. Akan tetapi dengan dukungan dari lingkungan keluarga maupun masyarakat mereka mampu untuk menambah kosa kata yang sering mereka dengarkan setiap harinya. Yanti (2016) bunyi-bunyi bahasa terjadi secara berurutan. Misalnya vokal minimal dapat diperoleh dari awal dibandingkan bunyi vokal lainnya. Sedangkan huruf konsonan lebih lambat diperoleh dari pada huruf vokal.

Tujuan dari artikel ini adalah mengetahui bagaimana pemerolehan bahasa pada anak usia dini di desa Hadiwarno, Mejobo Kudus. Batasan pemerolehan bahasa meliputi kata anggota keluarga, benda dalam rumah, benda di luar rumah, alat transportasi, hewan, warna, nama buah-buahan dan fenomena alam. Masing-masing anak tentu memiliki latar belakang pola asuh yang berbeda-beda. Hal ini juga berpengaruh kepada tahapan anak dalam memproduksi sebuah bahasa.

Desa Hadiwarno merupakan sebuah desa yang ada di Mejobo kabupaten kota Kudus. Artikel ini memilih lokasi penelitian di desa tersebut tentu memiliki pertimbangan. Di antara pertimbanganpertimbangan tersebut adalah di desa tersebut terdapat anak usia dini yang mempunya latar belakang yang bervariatif. Dengan latar belakang demikian, maka data yang diperoleh dalam artikel ini tentu akan memiliki daya tarik bagi pembaca.

Proses pemerolehan bahasa sangat dipengaruhi oleh pola asuh orang tua dan lingkungan masyarakat. Pada bayi dilahirkan memori bayi dapat diibaratkan sebagai kertas kosong yang kemudian hari akan terpatri oleh pengalaman-pengalaman yang mereka lalui. Gleason (1998) mengartikan bahwa perkembangan kognitif yang di dalamnya mencakup tentang bahasa kemudian dikemas sebaik mungkin dalam mengutarakan sudut pandang dari anak.

\section{Metode Penelitian}

Jenis penelitian ini adalah deskriptif kualitatif. Penelitian kualitaitaf merupakan salah satu metode yang memberikan perhatian terhadap data alamiah, data dalam hubunganya dengan konteks keberadaannya (Ratna, 2007:47). Objek penelitian yang ada dalam penelitian ini adalah dua anak, yang pertama anak berinisial "Z" umur 3,8 tahun dan yang kedua anak berinisial "B" dengan umur 3,1 tahun. Kajian yang digunakan dalam penelitian ini adalah menggunakan kajian psikolinguistik. Patteda (1990) psikolinguistik merupakan salah satu cabang linguistik yang digunakan sebagai alat untuk mengaplikasikan sebuah masalah dalam lingkup pemerolehan bahasa dan memproduksi suatu bahasa. 
Teknik pengumpulan data dalam penelitian ini menggunakan teknik observasi, wawancara dan dokumentasi. Teknik analisis data yang digunakan dalam penelitian ini adalah analisis deskriptif dengan menggunakan kerangka invention of tradition.

\section{Hasil dan Pembahasan}

Rusyini (2008) menjelasakan bahwa pada umumnya pemerolehan bahasa berasal dari lingkungan keluarga dan masyarakat. Tujuannya adalah untuk menjadi tuntunan komunikasi pada anak usia dini. Yang pertama adalah lingkungan keluarga, dalam hal ini anak menghabiskan waktu bermain di rumah. Selama di rumah yang berperan aktif di rumah adalah orangtua untuk menuntun anak dalam melafalkan ujaran. Kedua, lingkungan masyarakat di mana waktu anak untuk berinteraksi dengan tetangga dan teman sebaya. Lingkungan tersebut dapat dijadikan anak untuk bermain dan mempunyai dampak yang signifikan pada ujaran anak. Khomsyatun (2019) menjelaskan bahwa lingkungan bermain dapat berperan penting terhadap anak karena menyediakan anak berinteraksi atau bercakap-cakap. Semakin sering anak diajak untuk berinteraksi dengan masyarakat, maka kosa kata yang diperoleh anak pun sangat mempengaruhi.

Selain kedua faktor tersebut, Otto (2015) menambahkan bahwa ada faktor lain yang dapat mempengaruhi perkembangan atau kemampuan pemerolehan bahasa anak. Pertama adalah faktor alamiah dan kognitif. Faktor alamiah dapat dijelaskan bahwa proses pemerolehan melalui piranti yang bersifat alamiah. Misalkan meskipun anak tidak diajarkan berbicara akan tetapi anak dapat dengan sendirinya meniru bahasa yang diujarkan oleh ayah atau ibu. Kedua faktor perkembangan kognitif. Dari segi kognitif anak memiliki tingkat pemahaman tersendiri dalam memperoleh bahasa. Ketiga, faktir latar belakang sosial. Dalam struktur keluarga semakin tinggi ineraksi seuah keluarga semakin banyak peluang anggota keluarga dalam memperoleh bahasa. Yang terakhir adalah faktor keturunan. Di dalam faktor keturunan ada dua jenis antara lain jenis kelamin dan intelegensi.

Jenis kelamin dapat mempengaruhi pemerolehan anak, misalnya anak perempuan cenderung lebih cakap dalam berbicara dari pada anak laki-laki. Sedangkan faktor intelegensi adalah pemerolehan bahasa yang dapat dipengaruhi oleh kecerdasan yang dimiliki setiap anak, yakni IQ. Semakin IQ anak tersebut tinggi maka berpengaruh pula dengan kosa kata atau bahasa-bahasa yang didapatkannya.

Pembelajaran bahasa merupakan sebuah proses internalisasi sitem di mana proses tersebut berpengaruh pada transformasi bahasa. Pada saat bayi berusia enam bulan, dia akan melakukan atau menyuarakan celotehan khas bayi. Celotehan tersebut juga diawali dengan sebuah vokal dan konsonan. Setelah beranjak 1-4 tahun anak sudah dapat mengenali lingkungan sekitarnya serta mengenal anggota keluarga. Dalam tahap ini respon anak terhadap sesuatu sangatlah cepat.

Pemerolehan bahasa pada anak usia 1-4 tahun dipengaruhi oleh beberapa faktor antara lain, pola asuh keluarga, lingkungan dan asupan makanan. Desa Hadiwarno, Mejobo Kudus memiliki pola asuh dan latar belakang keluarga yang sangat bervariasi. Contoh sederhana panggilan ibu di keluarga A mengajarkan mamah, sedangkang keluarga B mengajarkan bunda. Hal ini tentu memiliki makna ketika orang tua mengajarkan sapaan kepada si anak.

Di dalam tabel 1 akan dirincikan bagaimana anak memeroleh bahasa mulai dengan menyebutkan kata kata anggota keluarga, benda dalam rumah, benda di luar rumah, alat transportasi, hewan, warna, nama buah-buahan dan fenomena alam. Dari setiap kosa kata tersebut ada beberapa klasifikasi benda yang belum dapat disebutkan oleh anak. 
Tabel 1. Pemerolehan Bahasa pada Anak Usia Dini di Desa Hadiwarno

\begin{tabular}{llll}
\hline No & \multicolumn{1}{c}{ Kata } & & Fon \\
\hline \multirow{2}{*}{$\mathbf{1}$} & Anggota Keluarga & & \\
& 1.Ayah & & \\
& 2.Ibu & $\mathbf{1 .}$ & papah \\
& 3.Kakak & $\mathbf{2 .}$ & mamah \\
& 4.Adik & $\mathbf{3 .}$ & kakak \\
& 5.Kakek & $\mathbf{4 .}$ & - \\
& 6.Nenek & $\mathbf{5 .}$ & - \\
& 7.Om & $\mathbf{6 .}$ & Eyang \\
& 8.Tante & $\mathbf{7 .}$ & Om \\
& & $\mathbf{8 .}$ & Tant $\partial$
\end{tabular}

2

\section{Benda-benda di dalam rumah}

1.Piring

2.Sendok

3.Gelas

4.Botol

5.Meja

6.Kursi

7.TV

8.Sapu

9.Kaca mata

10. Kipas angin

11. $\mathrm{AC}$

$\begin{array}{ll}\text { 1. } & \text { Iring } \\ \text { 2. } & \text { ndok } \\ \text { 3. } & - \\ \text { 4. } & \text { Susu } \\ \text { 5. } & - \\ \text { 6. } & - \\ 7 . & - \\ \text { 8. } & \text { Sapu } \\ \text { 9. } & - \\ \text { 10. } & - \\ \text { 11. } & -\end{array}$

3 Benda-benda di luar rumah

1.Pohon

2.Jalan

3.Rumput

4.Daun

5.Layang-layang

6.Batu

7.Awan

8.Bintang

9.Bulan

10.Matahari

Keterangan: Wawasan responden yang masih sedikit mempengaruhi sedikitnya ucapan yang dihasilkan
4 
5 Hewan

1.Ayam

1. ayam

2.Kucing

2. pus

3.Burung

3. hUlUng

4.Anjing

4. -

5.Ikan

5. -

6.Sapi

6. -

7.Kuda

7. uda

6

Warna

1.Merah

2.Kuning

3.Hijau

4.Dst.

Keterangan: Sama sekali belum mengetahui warna
$7 \quad$ Nama buah-buahan

1.Apel
2.Pisang
3.Manga
4.Semangka

$\begin{array}{ll}\text { 1. } & - \\ \text { 2. } & - \\ \text { 4. } & -\end{array}$

8

Fenomena alam
1.Hujan
2.Petir
3.Kilat
4.Pelangi
5.Mendung
6.Banjir
7.Dst.

$\begin{array}{ll}\text { 1. } & - \\ \text { 2. } & - \\ \text { 3. } & - \\ \text { 4. } & \text { s } \partial \text { m J ngk J }\end{array}$

Dari pemaparan data di atas, anak berinisial " $Z$ " dan "B" hanya memiliki cakupan pengetahuan tentang benda-benda, fenomena alam bahkan, belum mengetahui sama sekali tentang warna-warna. Hal ini dikarenakan dari lingkungan keluarga masih sedikit mengajarkan tentang warna. Data tertinggi dalam pemerolehan bahasa adalah penebutan anggota keluarga. Dalam hal ini anggota keluarga dalam sehari-hari anak selalu menjumpai, berinteraksi dan saling menyapa. Dari faktor rutinitas tersebut, secara tidak langsung anak dapat menyebutkan anggota keluarga. Selain itu anak juga dapat mengenali benda-benda yang ada di dalam maupun luar rumah. Hal ini dikarenakan waktu sehari-hari anak dihabiskan dilingkungan tersebut dan kerap menjumpainya.

Pada usia tersebutlah anak masih terus belajar untuk mengungkapkan kata dengan lafal yang jelas. Di usia 3 tahun mereka masih tampak kesulitan dalam memnyampaikan atau mengungkapkan fonem "R" dan belum sempurna. Akan tetapi kembali kepada pendapat Khomsyatun dan Otto bahwa pemerolehan bahasa tidak hanya dipengaruhi oleh beberapa faktor keluarga, sekolah dan lingkungan atau masyarakat, akan tetapi dipengaruhi pula dengan faktor alamiah dan kognitif. Faktor lingkungan rumah dan lingkungan masyarakat dampaknya sangat besar. Pada usia dinilah otak akan berpengaruh dengan cepat untuk menstimulasi bahasa-bahasa yang di dengar baik di rumah maupun lingkungan masyarakat. 
Dari pengamatan peneliti, pola asuh mendidik anak juga dapat memeengaruhi bahasa anak. Misalkan pada anak " $Z$ " kosa kata yang dimiliki cenderung lebih banyak. Hal ini dikarenakan bahwa " $Z$ " mempunyai orang tua yanng berprofesi sebagai guru. Dia sering diajarkan berbicara dan melafalkan anggota keluarga serta benda yang ada di dalam maupun di luar rumah. "Z" juga sering diberikan buku-buku misalkan gambar-gambar sehingga dia lebih banyak mengungkapkan kata sesuai apa yang diajarkan orang tuanya.

\section{Kesimpulan}

Proses pemerolehan bahasa sangat dipengaruhi oleh pola asuh orang tua dan lingkungan masyarakat. Selain itu aspek alamiah dan kognitif juga berperan di dalamnya. Pada pola asuh tiap orang tua pada penelitian ini juga sangat mempengarui dengan kebiasaaan-kebiasaan yang diajarkan orang tua kepada anak. Meskipun mereka masih kesulitan dalam memproduksi huruf konsonan, akan tetapi anakanak tersebut telah berusahan untuk menyampaikan dengan lafal yang mereka miliki. Pada bayi dilahirkan memori bayi dapat diibaratkan sebagai kertas kosong yang kemudian hari akan terpatri oleh pengalaman-pengalaman yang mereka lalui. Hasil dari penelitian ini adalah dari kata anggota keluarga, benda dalam rumah, benda di luar rumah, alat transportasi, hewan, warna, nama buah-buahan dan fenomena alam. Pemerolehan data tertinggi adalah menyebutkan nama anggota keluarga. Hal ini dikarenakan, dalam proses pemerolehan bahasa yang terjadi pada anak usia dini, kosa kata akan lebih banyak terbentuk dari keluarga. Sebaiknya dalam usia dini seperti ini anak kerap diajarkan untuk berinteraksi dengan lingkungan sosial agar mereka dapat mestimulus bahasa atau kosa kata baru yang terekam dalam otak anak-anak. Sebagai orang tua berkewajiban untuk selalu mengeksplor pengetahuan anak kepada keluarga, lingkungan atau tempat bermain yang mereka jumpai.

\section{Daftar Pustaka}

Fatmawati, S. R. (2015). Pemerolehan bahasa pertama anak menurut tinjauan psikolinguistik. Lentera, 17(1).

Gleason dan Ratner. (1998). Psycolinguistics (second edition). United Stated: Harcourt Brace College Publishers

Handke. (2012). Psycholinguistics - Introduction. The Virtual Linguistic Campus

Hakim. (2012). Psikolinguistik dan Kajiannya. New York: Columbia University

Hastuti, S. K. (2018). Analisis pemerolehan bahasa pertama (bahasa melayu) pada anak usia 3 tahun. Jurnal Pena Indonesia, 4(1), 106-114.

Khomsiyatun, U. (2019). Proses Pemerolehan Bahasa Pertama Pada Anak Usia Dini: Studi Kasus Di Paud Wadas Kelir Purwokerto. Equalita: Jurnal Studi Gender dan Anak, 1(1), 95-113.

Mayasari. (2018). Publikasi bentuk fungsi dan kategori sintaksis tuturan masyarakat Manduro sebagai pendukung perkembangan bahasa anak usia dini. Jurnal Obsesi, 2(1).

Nurjamiaty, N. (2015). Pemerolehan Bahasa Anak Usia Tiga Tahun Berdasarkan Tontonan Kesukaannya Ditinjau Dari Kontruksi Semantik. Jurnal Edukasi Kultura: Jurnal Bahasa, Sastra dan Budaya, 2(2).

Nyoman, K. R. (2009). Teori, Metode, dan Teknik Penelitian Sastra. Yogyakarta: Pustaka Pelajar

Otto, B. (2015). Perkembangan Bahasa Pada Anak Usia Dini. Jakarta: Prenada

Patteda, M. (1990). Aspek-aspek Psikolinguistik. Flores: Nusa Indah

Pramita, C. (2019). Pemerolehan Bahasa Anak Usia 3; 5 Tahun (Studi Kasus Pada Raja). Jurnal Edukasi Khatulistiwa: Pembelajaran Bahasa dan Sastra Indonesia, 2(2), 8-12. 
Puspitasari, R. H., \& Safitri, P. I. (2016). Penguasaan bahasa pertama (mother tongue) pada batita dan balita transmigran asal Jawa di Silat Kapuas Hulu Kalimantan Barat: Kajian psikolinguistik. Prosiding Prasasti, 646-652.

Rusyani, E. (2008). Pemerolehan Bahasa Indonesia Anak Usia 2, 5 Tabun (Studi Kasus terhadap Pemerolehan Bahasa Anak Usia Dini). Skripsi. Fakultas Ilmu Pendidikan Universitas Pendidikan Indonesia.

Suardi, I. P., Ramadhan, S., \& Asri, Y. (2019). Pemerolehan bahasa pertama pada anak usia dini. Jurnal Obsesi: Jurnal Pendidikan Anak Usia Dini, 3(1), 265-273.

Syaprizal, M. P. (2019). Proses Pemerolehan Bahasa pada Anak. AL-HIKMAH Jurnal Pendidikan Dan Pendidikan Agama Islam), 1(2), 75-86.

Tarigan, H. G. (2008). Membaca sebagai Suatu Keterampilan Berbahasa. Bandung: Angkasa

Yanti, P. G. (2016). Pemerolehan bahasa anak: kajian aspek fonologi pada anak usia 2-2, 5 tahun. Jurnal Ilmiah Visi, 11(2), 131-141.

Viandari, K. D. \& Kadek Pande A.S. (2019). Peran Pola Asuh Orang Tua Dan Penggunaan Gadget Terhadap Interaksi Sosial Anak Prasekolah. Jurnal Pesikologi Udayana. 6 (1). 76-87. 